\title{
Parâmetros genéticos da resistência ao complexo da queima-das-folhas em populações de cenoura
}

\author{
Giovani O Silva; Jairo V Vieira; Michelli S Vilela; Ailton Reis; Leonardo S Boiteux
}

Embrapa Hortaliças, C. Postal 218, 70351-970 Brasília-DF; olegario@cnph.embrapa.br

\begin{abstract}
RESUMO
Os parâmetros genéticos vinculados ao complexo de patógenos causadores da queima-das-folhas de cenoura foram determinados utilizando famílias de meio-irmãos oriundas de populações do grupo varietal 'Brasília'. Ainda, verificou-se quais populações eram capazes de proporcionar maior ganho para este caráter. O experimento foi conduzido em Brasília entre novembro/06 e fevereiro/07. Foram avaliadas cinco populações em fase final de melhoramento (processamento $1(\mathrm{P} 1)$, processamento 2 (P2), mesa 3 (M3), mesa 4 (M4) e mesa 5 (M5), utilizando delineamento em blocos ao acaso com duas repetições (parcelas de $2 \mathrm{~m}^{2}$ ). A avaliação da severidade da queima-das-folhas foi feita aos 90 dias após semeio e os dados foram submetidos à análise de variância para estimar os parâmetros genéticos e o ganho direto esperado com a seleção. O caráter resistência à queima-das-folhas apresentou-se significativo em diferenciar as populações. A população P1 mostrou os maiores valores dos parâmetros genéticos e ganhos esperados com a seleção, ao passo que a população M3 mostrou-se a menos promissora na obtenção de ganhos para níveis mais elevados de resistência. Os valores da relação entre os coeficientes de variação genética e ambiental e de herdabilidade foram baixos. Estes dados podem ser explicados pela ausência de variabilidade genética nas populações, mas também podem indicar a necessidade de um maior refinamento nos processos de avaliação e de inoculação em condições de campo, de forma a garantir o estabelecimento de epidemias mais uniformes da queima-das-folhas nas parcelas experimentais.
\end{abstract}

Palavras-chave: Daucus carota L., Alternaria dauci, Cercospora carotae, Xanthomonas campestris pv. carotae.

\begin{abstract}
Genetic parameters of the resistance to the leaf blight disease complex in carrot populations

The genetic parameters associated with resistance to the carrot leaf blight disease complex were evaluated using half-sib families derived from the varietal group 'Brasília'. We also evaluated which populations would provide larger gains for this character. Field assay was carried out in Brasília during the summer season (from November 2006 to February 2007). Five advanced breeding populations (processing $1(\mathrm{P} 1)$, processing $2(\mathrm{P} 2)$, table $3(\mathrm{M} 3)$, table 4 (M4) and table 5 (M5), were evaluated using an experimental design of completely randomized block with two replicates. The total area per plot was of $2 \mathrm{~m}^{2}$. Evaluation for leaf blight symptom severity was done 90 days after sowing. ANOVA was used to estimate genetic parameters and the genetic gain from selection. Leaf blight resistance levels were significant and allowed the discrimination of the populations under evaluation. According to the genetic parameters and the expected gains with selection, the population P1 was the most and M3 was the less promising genetic material aiming to improve leaf blight resistance levels in Brasília-type carrots. The values of the relationship among the genetic and environmental variation coefficients and heritability were low. Apparently, genetic variability for leaf blight resistance in the populations under study is already depleted. On the other hand, it might also indicate the need for refinement in both the evaluation system as well as in the inoculation technique, which are crucial to allow uniform epidemics of the leaf blight complex across field plots.
\end{abstract}

Keywords: Daucus carota L., Alternaria dauci, Cercospora carotae, Xanthomonas campestris pv. carotae.

\section{(Recebido para publicação em 8 de dezembro de 2008; aceito em 29 de junho de 2009)} (Received in December 8, 2008; accepted in June 29, 2009)

\begin{abstract}
$\mathrm{A}$ cenoura é uma das principais hortaliças produzidas no Brasil, onde a maioria das cultivares para o verão foram melhoradas por instituições brasileiras públicas ou privadas. Entretanto, ainda existe pouca informação formalmente registrada sobre os detalhes metodológicos aplicados durante o processo de desenvolvimento dessas cultivares (Vieira et al., 2006).

O sucesso do cultivo de cenoura em condições de verão tropical é devido principalmente ao reduzido florescimento prematuro e à resistência a doenças
\end{abstract}

que ocorrem nessas condições. Dentre as doenças da cultura, a queima-das-folhas é uma das mais comuns, com ocorrência em praticamente todas as regiões onde se cultiva esta hortaliça, principalmente nas épocas mais quentes e úmidas do ano (Henz \& Lopes, 2000).

A doença é causada por um complexo etiológico envolvendo dois fungos, Alternaria dauci (Ad) e Cercospora carotae (Cc), e a bactéria Xanthomonas campestris pv. carotae (Reifschneider, 1984). Os três patógenos podem estar presentes de maneira isolada ou simul- taneamente em uma lavoura, planta ou folha. Um grande problema na avaliação para a resistência a estes patógenos é o fato que todos induzem sintomas muito semelhantes em cenoura (Reifschneider, 1984). Entretanto, mais recentemente, levantamentos extensivos têm demonstrado que na maioria das lavouras comerciais, a queima-das-folhas é causada principalmente pelas duas espécies fúngicas (Lopes et al., 2000).

O método de controle mais eficiente para esta doença tem sido feito com o uso de variedades resistentes (Lopes et 
al., 2000) em combinação com o uso de fungicidas (Henz \& Lopes, 2000).

Em condições de alta umidade, a queima-das-folhas afeta quase exclusivamente a parte aérea, tendo impactos negativos na produção e qualidade das raízes (Henz \& Lopes, 2000). Em avaliação feita no período de verão em Uberlândia-MG, Juliatti et al. (1996) concluíram que a severidade da queimadas-folhas apresentou correlação alta e negativa $(-0,77)$ com o peso de raízes comerciais, implicando em severas perdas econômicas.

Nos cultivos em verões chuvosos, a utilização de cultivares suscetíveis pode implicar na necessidade de cerca de 50 aplicações de fungicidas por safra (Reifschneider et al., 1984). Além de aumentar os custos de produção e a poluição ambiental, existem relatos que indicam que o uso intensivo do controle químico pode induzir ao surgimento de variantes de $A$. dauci resistentes a certos princípios ativos (Fancelli \& Kimati, 1990).

O objetivo do presente trabalho foi determinar parâmetros genéticos associados à resistência a queima-dasfolhas em cenoura utilizando famílias de meio-irmãos oriundas de populações do grupo 'Brasília' em processo de melhoramento.

Esta informação é fundamental na definição de estratégias que subsidiem sistemas eficientes de seleção para o caráter e para identificar as populações que apresentam maior potencial de ganhos genéticos para resistência a este complexo etiológico.

\section{MATERIAL E MÉTODOS}

O experimento foi conduzido na Embrapa Hortaliças de novembro/2006 a fevereiro/2007. Foram avaliadas cinco populações de cenoura todas na $23^{\mathrm{a}}$ geração de seleção recorrente.

Três populações foram desenvolvidas para o mercado tradicional de cenoura: 0612439 (M3), 0612441 (M4) e 0612437 (M5); e duas especificamente para processamento mínimo: 0612424 (P1), 0612438 (P2). As populações foram compostas de 119, 89, 102, 106 e 114 famílias de meio-irmãos, respec- tivamente. Foi utilizado o delineamento de blocos ao acaso com duas repetições. O tamanho de parcela foi de $2 \mathrm{~m}^{2}$.

A infecção das plantas nas parcelas ocorreu naturalmente, sem inoculação. Os níveis naturais de inóculo foram considerados adequados pela severa e uniforme infecção de algumas parcelas.

As avaliações para severidade de queima-das-folhas nas parcelas foram efetuadas aos 90 dias após o plantio utilizando-se uma adaptação da escala de notas de severidade da doença proposta por Aguilar et al. (1986) onde: 1= parcelas com sintomas severos, ou seja, todas as folhas da parcela totalmente necrosadas a $5=$ parcelas sem sintomas.

As notas de severidade em cada parcela foram atribuídas em conjunto por três avaliadores, comparando-se com parcelas de cultivares utilizadas como testemunhas resistentes: 'Alvorada' (para as populações de consumo tradicional) e 'Esplanada' (para as populações de processamento) e 'Brasília' (para ambas).

Não houve aplicação de fungicida ou outro agente químico durante o experimento para controle dos patógenos.

Os dados foram transformados (raiz quadrada da nota) para atender a pressuposição de normalidade de distribuição. Foi realizada uma análise de variância conjunta para as populações. As dife- rentes populações corresponderam aos tratamentos e as médias das populações foram comparadas pelo teste de Duncan (a 5\% de probabilidade de erro).

Foram realizadas também análises de variância para cada população, com o objetivo de estimar as médias, a herdabilidade $\left(\mathrm{h}^{2}\right)$, os coeficientes de variação fenotípico (CVe) e genotípico (CVg), a relação $\mathrm{CVg} / \mathrm{CVe}$.

Os ganhos diretos decorrentes da seleção (GS) de 50\% das famílias foram calculados pela fórmula $\mathrm{GS}=[\mathrm{ds} \mathrm{x}$ $\left.\mathrm{h}^{2}\right]$ onde $\mathrm{ds}=$ diferencial de seleção. As análises foram realizadas utilizandose o aplicativo computacional Genes (Cruz, 1997).

\section{RESULTADOS E DISCUSSÃO}

As populações diferiram estatisticamente quanto à resistência à queimadas-folhas de acordo com a análise de variância conjunta. Da mesma forma, este caráter apresentou-se significativo em diferenciar as famílias estudadas pela análise de variância para cada população (dados não mostrados).

A população M5 apresentou a menor média, ou seja, foi a mais suscetível. Já as populações P1, P2, M3 e M4 não diferiram pela comparação de médias, porém mostraram desempenho diferen-

Tabela 1. Médias de populações, das testemunhas ('Brasília', 'Esplanada' e 'Alvorada'), relação entre coeficiente de variação genético e ambiental $(\mathrm{CVg} / \mathrm{CVe})$, herdabilidade $\left(\mathrm{h}^{2}\right)$, diferencial e ganho de seleção, para populações de cenoura avaliadas para queima-das-folhas (population means of 'Brasília', 'Esplanada' and 'Alvorada', relationhip between genetic and environmental coefficients $(\mathrm{CVg} / \mathrm{CVe})$, heritability $\left(\mathrm{H}^{2}\right)$, differential and gain with selection, of five carrot populations evaluated for leaf blight). Brasília, Embrapa Hortalicas, 2007.

\begin{tabular}{llllll}
\hline & \multicolumn{5}{c}{ Populações } \\
\cline { 2 - 6 } & \multicolumn{1}{c}{ P1 } & \multicolumn{1}{c}{ P2 } & M3 & M4 & M5 \\
\hline Média da população & $1,80 \mathrm{a}^{1}$ & $1,79 \mathrm{a}$ & $1,78 \mathrm{a}$ & $1,80 \mathrm{a}$ & $1,76 \mathrm{~b}$ \\
Média de Brasília & 1,50 & 1,58 & 1,58 & 1,58 & 1,52 \\
Média de Alvorada/Esplanada & 1,78 & 1,73 & 1,68 & 1,70 & 1,58 \\
Relação CVg/CVe & 1,10 & 0,49 & 0,48 & 0,78 & 0,84 \\
$\mathrm{H}^{2}$ & 0,71 & 0,33 & 0,31 & 0,55 & 0,58 \\
Diferencial de seleção & 0,09 & 0,10 & 0,09 & 0,08 & 0,09 \\
Ganho de seleção & 3,55 & 1,76 & 1,54 & 2,40 & 2,99 \\
\hline
\end{tabular}

${ }^{1}$ Médias da população seguidas de letras diferentes na linha diferiram significativamente por

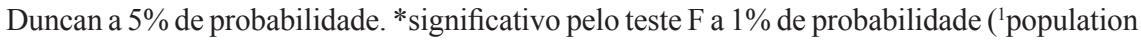
means with different letters in the line differ significantly by Duncan at $5 \%$ of probability. * significant by $\mathrm{F}$ test at $1 \%$ of probability). 
ciado quanto aos valores de herdabilidade e da relação $\mathrm{CVg} / \mathrm{CVe}$, que em geral foram baixos.

Estes resultados sugerem que a variabilidade genética na população foi baixa ou que houve predominância de variância de ordem ambiental. Um modo de minimizar este último fator envolve um maior refinamento nos processos de avaliação e de inoculação em condições de campo, de forma a garantir o estabelecimento de epidemias mais uniformes da queima-das-folhas entre as parcelas experimentais.

Apesar disso, estas estimativas mostraram-se semelhantes na indicação da população mais promissora para aumentar-se a tolerância à queima-das-folhas (população P1), com relação $\mathrm{CVg} / \mathrm{CVe}$ superior a 1,0 e herdabilidade superior a $70 \%$; indicando que para esta população houve predominância de variância de ordem genética (Tabela 1).

Estimativa de herdabilidade próxima aos valores observados neste trabalho, principalmente pelas populações P2 e M3, foi verificada por Boiteux et al. (1993), também para a população de meio-irmãos do grupo Brasília, com valor de 0,40 ; mesmo valor da estimativa obtida por Della Vecchia \& Reifschneider (1983), estudando populações derivadas do grupo Kuroda; e muito semelhante também ao valor de 0,39 obtido por Vilela (2008), em sistema orgânico de produção.

A resistência à queima das folhas em cenoura é sabidamente de herança quantitativa e portanto, de forte influência ambiental (Shibata et al., 2008).

A variação dos valores de herdabilidade de 0,31 a 0,71 do presente trabalho também se assemelham aos valores obtidos com populações de cenoura por Vieira et al. (1991), com valores variando de 0,45 a 0,82 . A razão entre os coeficientes de variação genético e ambiental, estimada por Vieira et al. (1991) entre 0,55 e 1,48, também foi muito semelhante à estimativa obtida no presente trabalho $(0,48$ a 1,10$)$.

De acordo com estes dados, para algumas populações, como P1, M4 e M5, os ganhos esperados com a seleção podem ser compensadores, e o contrário pode ser verificado para P2 e M3.

Os ganhos com a seleção confirmam a superioridade da população P1 $(3,55 \%)$, ou seja, a nova população obtida pela combinação entre as famílias selecionadas, será 3,55\% mais resistente que a população da qual esta se originou. Já a população M3 apresentou os menores ganhos esperados com a seleção $(1,54 \%)$.

Estes ganhos contrastantes dão suporte ao que foi indicado pelos valores da relação entre CVg e CVe e herdabilidade que foram superiores para a população P1 e inferiores para M3.

As demais populações obtiveram ganhos com a seleção com valores intermediários aos citados anteriormente (1,76 a 2,99), valores também proporcionais à herdabilidade e relação entre os coeficientes de variação. Pelos valores das médias, pode-se verificar que, em geral, as testemunhas (Brasília, Esplanada e Alvorada) foram inferiores às populações estudadas, ou seja, com maiores médias, indicando a possibilidade de se desenvolver cultivares superiores às testemunhas em relação à queima-das-folhas (Tabela 1).

Os valores da relação entre os coeficientes de variação genética e ambiental seguem a tendência daqueles da herdabilidade, que foram baixos.

Estes dados podem ser explicados pela ausência de variabilidade genética nas populações, mas também indicam a necessidade de um maior refinamento tanto no processo de avaliação como na necessidade de inoculação em condições de campo.

A população P1 apresentou os maiores valores dos parâmetros genéticos possibilitando maiores ganhos com a seleção.

A população M3, apesar de estar entre as populações com maior média, proporcionaria pequenos ganhos com a seleção devido à reduzida herdabilidade.

\section{REFERÊNCIAS}

AGUILAR JAE; REIFSCHNEIDER FJB; ROSSI PFE; DELLA VECCHIA PT. 1986. Nível de resistência de cenoura a Alternaria dauci e interação com tratamento químico. Horticultura Brasileira 41: 9-22.

BOITEUX LS; DELLA VECCHIA PT; REIFSCHNEIDER FJB. 1993. Heritability estimate for resistance to Alternaria dauci in carrot. Plant Breeding 110: 165-167.

CRUZ CD. 1997. Programa Genes: Aplicativo Computacional em Genética e Estatística. Viçosa: UFV. 442p.

DELLA VECCHIA PT; REIFSCHNEIDER FJB. 1983. Estimativa de herdabilidade da resistência a Alternaria dauci em cenoura. In: CONGRESSO BRASILEIRO DE OLERICULTURA, $23^{\circ}$. Resumos... Rio de Janeiro: SOB. 141pp.

FANCELLI MI; KIMATI H. 1990. Ocorrência de linhagens de Alternaria dauci resistentes ao fungicida iprodione. Summa Phytopathologica 16: $252-256$

HENZ GP; LOPES CA. 2000. Doenças das apiáceas. In: ZAMBOLIN L; VALE FXR; COSTA H. (eds.). Controle de Doenças de Plantas - Hortaliças. Viçosa: UFV. 445-522 p.

JULIATTIFC; OLIVEIRAFILHO GM; PEIXOTO JR. 1996. Resistência de cultivares de cenoura à queima das folhas (Alternaria dauci) no verão, em Uberlândia-MG. Horticultura Brasileira 14: 33-35.

LOPES CA; RITSCHEL PS; VIEIRA JV; LIMA DB. 2000. Comportamento de genótipos de cenoura para verão em localidades com diferentes etiologias de queima-das-folhas. Horticultura Brasileira 18: 119-122.

REIFSCHNEIDER FJB. 1984. Doenças fúngicas e bacterianas da cenoura - sintomatologia e controle. Informe Agropecuário 10: 40-43.

SHIBATAET; REIS A; VIEIRA JV. 2008. Reação de cultivares de cenoura à queima das folhas em campo e à Alternaria dauci em casa-devegetação. Brasília, Embrapa. Boletim de pesquisa e desenvolvimento $47.14 \mathrm{p}$.

VIEIRA JV; CASALI VWD; MILAGRES JC; CARDOSO AA; REGAZZI AJ. 1991. Heritability and genetic gain for resistance to leaf blight in carrot (Daucus carota L.) populations evaluated at different times after sowing. Revista Brasileira de Genética 14: 501-508.

VIEIRA JV; NASCIMENTO WM; SILVA JBC. 2006. Número mínimo de populações de meios-irmãos para avaliação de uma população de cenoura. Pesquisa Agropecuária Brasileira 41: 365-367.

VILELA MS. 2008. Estimativas de parâmetros genéticos para caracteres de cenoura em sistemas de cultivo agroecológico. Brasília: UnB. 68p. (Tese mestrado). 